\title{
O teatro experiencial de Mark Ravenhill
}

\section{Francesca Rayner}

\section{Algumas polaroides \\ explicitas, \\ de Mark Ravenhill, \\ enc. Manuel Guede Oliva, \\ Companhia de Teatro de \\ Braga, 2003 \\ (Ana Bustorff), \\ fot. Carlos Sampaio.}

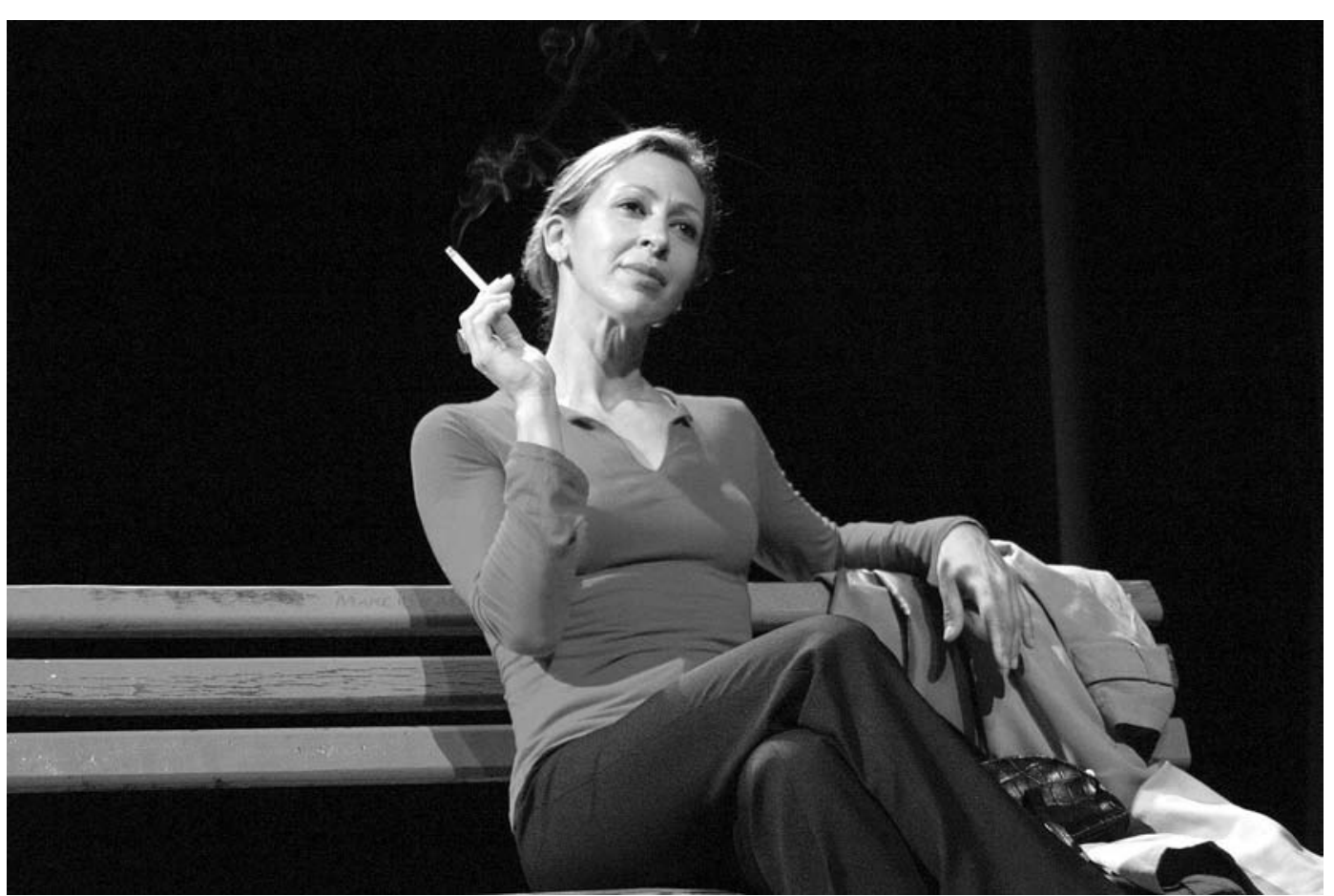

Titulo: Product (2005) Autor:Mark Ravenhill. Encenação: Lucy Morrison. Interpretação: Mark Ravenhill. Figuração: Sofia Correia. Desenho de som e luz: Mat Ort. Produção: Paines Plough e Mark Ravenhill. Local e data de apresentação: Culturgest, Lisboa, 27 de Abril de 2006.

Mark Ravenhill é um dos mais versáteis e acutilantes dramaturgos ingleses da actualidade. A sua primeira peça - Shopping and Fucking (1996) - é uma crítica mordaz ao consumismo e aos seus efeitos sobre as relações pessoais, tendo ajudado a redefinir o teatro inglês nos anos 90. As peças que a seguir escreveu, como Faust is Dead (1997), Handbag (1998), Some Explicit Polaroids (1999) e Mother Clap's Molly House (2001) abordavam questões actuais tais como a futilidade do culto da celebridade, o papel do individuo num mundo de imagens globalizadas, a paternidade numa era de engenharia biológica, bem como a diversidade dos papéis sexuais.

No contexto português, Ravenhill passou pelos palcos esporadicamente. 0 Teatro Plástico encenou Shopping and Fucking no Auditório Nacional Carlos Alberto do Porto em 1999. Esta produção foi sujeita a várias pressões para que o espectáculo não se realizasse, mas fez-se e foi um grande sucesso junto do público, sobretudo o mais jovem. A Companhia de Teatro de Braga produziu Algumas polaroides explícitas em 2003 numa tradução de Regina Guimarães, e Fausto morreu foi co-produzido pela Metamorfose Total e Casa d'Os Dias da Água em 2005 numa tradução, encenação e interpretação de Carlos
Afonso Pereira. Em Junho de 2006, a Culturgest promete levar à cena Cidadania (Citizenship, 2005) numa tradução de Jorge Louraço Figueira, no âmbito do Festival PANOS.

Ravenhill é frequentemente associado, tal como Sarah Kane e Anthony Nielson, à geração teatral in-yer-face. Esta expressão foi utilizada pelo crítico Aleks Sierz para sublinhar a frontalidade deste teatro, que choca pelo extremismo da linguagem e das imagens e pela sua franqueza afectiva e sexual. Sierz descreve-o como sendo um teatro experiencial com o objectivo de provocar emoções fortes no público através da representação de emoções fortes no palco. Ravenhill é também considerado um dramaturgo queer pelo seu incómodo questionamento de normas morais, a procura, por parte das suas personagens, de famílias alternativas à família biológica, bem como o desrespeito por barreiras normativas entre a homossexualidade e a heterossexualidade. Em contraste com a geração anterior de dramaturgos gays, as suas personagens não reclamam o direito à igualdade, mas sim 0 direito à diferença.

No entanto, o teatro de Ravenhill é mais diversificado, não correspondendo a um corte total com o passado teatral como estes dois rótulos críticos podem sugerir. 


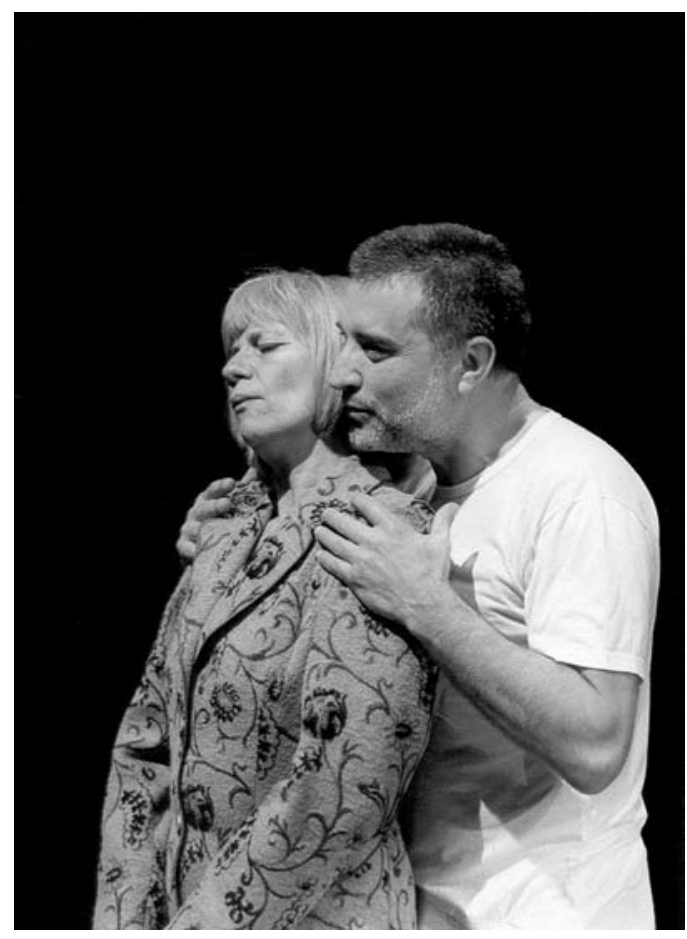

Ravenhill frequentemente escreve peças onde narrativas teatrais conhecidas são adaptadas a situações contemporâneas, como é o caso de Handbag "a partir de" de A importância de ser Ernesto, de Wilde, e Totally Over You (2003) a partir de Les Precieuses Ridicules, de Molière. Como a geração anterior de dramaturgos do Royal Court, trabalha em estreita colaboração com actores e encenadores, em companhias que são sucessoras desta tradição como Out of Joint e Paines Plough. 0 seu teatro pode não ser visto como "político" da maneira que a geração de Brenton, Bond e Hare entendiam a política, sobretudo porque não tem uma visão unificadora de classe nem da história. No entanto, detecta-se no aparente niilismo das suas peças uma raiva nitidamente política contra uma sociedade desumanizada, na qual tudo se pode comprar. A vertente ética do seu trabalho é sublinhada pelo próprio Ravenhill quando afirma que "há sempre um momento em que as minhas personagens reconhecem que têm de cuidar umas das outras"'. Este reconhecimento é figurado no acto simples de dar de comer que une Robbie, Mark e Lulu em Shopping and Fucking, ou na negociação complexa de uma comunidade entre pessoas com diversas sexualidades dentro do bordel homossexual em Mother Clap's Molly House. A sua preocupação política e ética é visível noutros aspectos da sua prática teatral, nomeadamente no seu trabalho para/com jovens, como

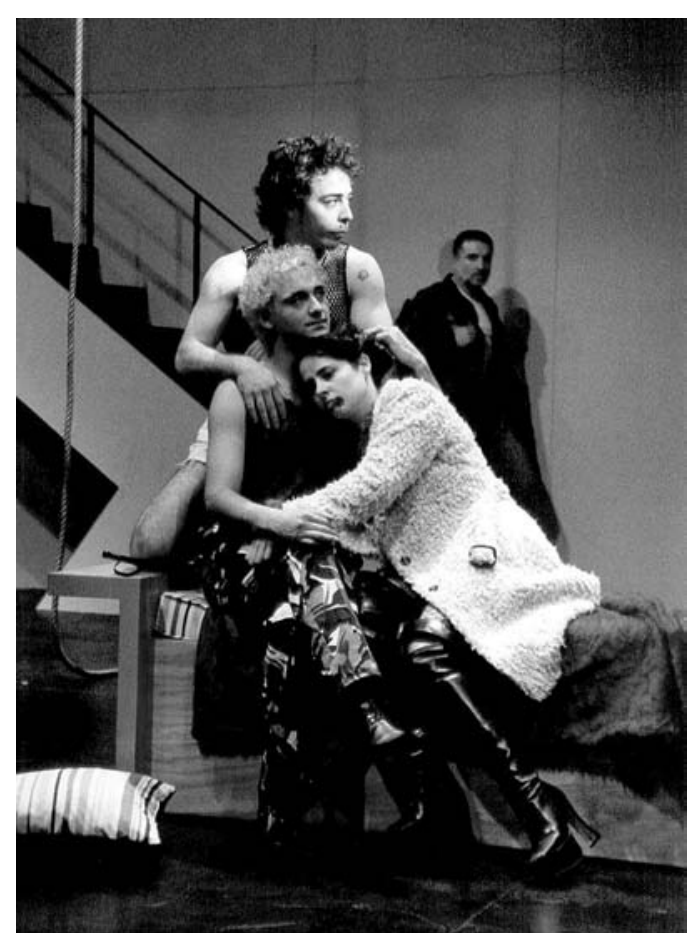

Algumas polaroides

explicitas,

de Mark Ravenhill,

enc. Manuel Guede Oliva, Companhia de Teatro de Braga, 2003 (Guida Maria e Rui Madeira), fot. Manuel Correia.

Algumas polaroides explicitas, de Mark Ravenhill, enc. Manuel Guede Oliva, Companhia de Teatro de Braga, 2003 (Solange Sá, Jaime Monsanto, João Melo e Rui Madeira), fot. Manuel Correia.

é o caso de Cidadania, por exemplo, sobre um jovem que busca a sua identidade sexual.

Product, o espectáculo que Ravenhill apresentou na Culturgest (deixo aqui a minha perplexidade pelo facto de este espectáculo ter sido tão pouco divulgado pela própria Culturgest e pela imprensa), foi originalmente encenado pelo Traverse Theatre de Edimburgo em 2005. Partiu de uma sensação de mal-estar do próprio Ravenhill de que a sua notoriedade o tinha tornado numa imagem de marca, facilmente reconhecida e vendida internacionalmente. Talvez por isto, Ravenhill queria ver até que ponto o acto teatral podia ser reduzido aos seus elementos mais simples: um bom texto, um intérprete carismático e um público interessado em ouvir.

Pela primeira vez, Ravenhill aparece como actor numa das suas peças. A sua presença física - alto, forte, de cabeça rapada e uma voz poderosa - é algo intimidatória, mesmo quando sentado. Por isso, funciona como complemento perfeito à intensidade oral do seu monólogo. Este monólogo decorre a um ritmo avassalador, numa verdadeira torrente de palavras que desafia não só o actor como também aqueles que estão menos à vontade no inglês. A encenação é básica e a actriz que acompanha Ravenhill no palco é uma presença passiva. Por isso, o espectáculo concentra-se na interacção entre o actor e o texto.
Entrevista com Aleks Sierz em www.inyerfacetheatre. com (8/5/2006) 
0 monólogo conta a história de um realizador de cinema que tenta vender um guião a uma jovem actriz, e a apresentação pelo realizador deste "produto" serve para interrogar dois temas bastante actuais - o das relações possiveis entre ocidentais e muçulmanos, num mundo de mútuos medos e suspeitas, e o tratamento redutor de temas complexos feito pela indústria cultural.

0 guião que o realizador (James) quer vender à actriz (Olivia) inclui os piores clichés do mundo cinematográfico contemporâneo levados ao seu extremo: "Bridget Jones junta-se à jihad" como o próprio Ravenhill ironiza. Propõe uma história de amor entre Amy, uma jovem ocidental, e o muçulmano Mohammed, que se encontram num avião. Há desconfiança dos dois lados, mas a paixão entre os dois cresce. Depois de uma reunião política conspirativa em casa de Amy, a que compareceu o próprio Osama Bin Laden, os dois aceitam uma missão suicida na Eurodisney. A história parece acabar quando Amy decide denunciar o seu amante aos serviços secretos, mas logo de seguida, inexplicavelmente, substitui-se por um outro "final feliz" em que Amy tenta salvar o seu amante da prisão.

Mohammed morre acidentalmente, e Amy acaba jurando vingança a Alá.

0 sentimentalismo desta narrativa é não só subvertido pelo absurdo, como também constantemente interrompido pelos comentários fátuos e cínicos do realizador ("o coração é um orgão maior do que a cabeça neste negócio a que chamamos espectáculo"). A tensão entre o guião e a sua apresentação pelo realizador permite que nunca se perca a consciência do que se trata de um produto cultural para venda. Este dialogismo do texto de Ravenhill (em flagrante contraste com o monologismo do guião) permite múltiplos pontos de vista e provoca emoções fortes e complexas nos espectadores. A certa altura, o texto descreve o sonho de Amy em que uma criança na Eurodisney avança inconscientemente para a mulher bombista à procura da sua "mamã". A expectativa do momento antes de a bomba rebentar é intensificada pelo aparecimento casual do rato Mickey. A seguir à explosão da bomba, descreve-se a cabeça da criança voando pelos ares de uma forma em que o público não distingue facilmente entre a tragédia da morte da criança e o modo burlesco da sua descrição. Poderíamos até argumentar que o episódio recria - num ambiente actual - a terrivel cena de apedrejar uma criança na peça Saved (1965), de Edward Bond.

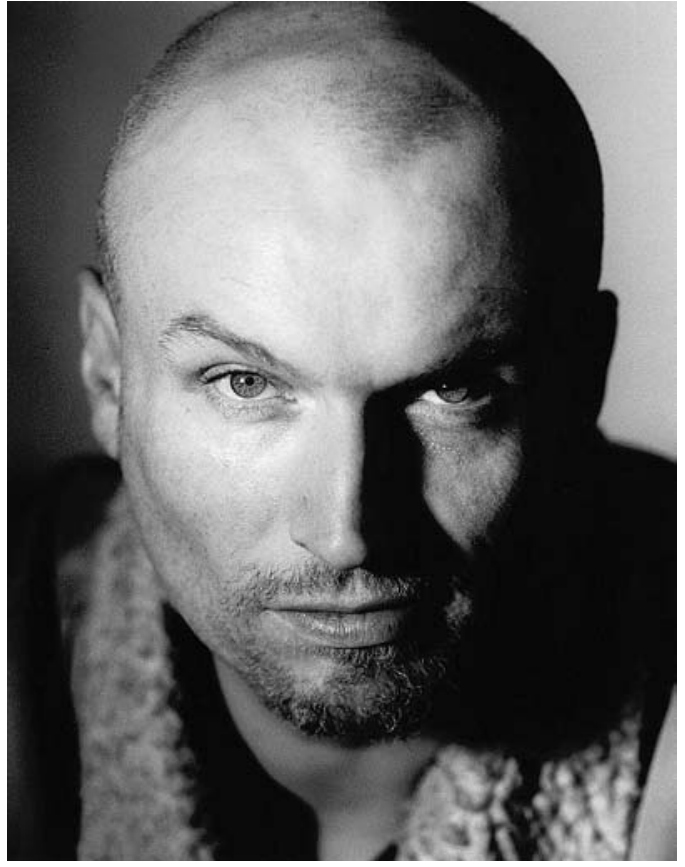

As várias etapas da relação entre o muçulmano Mohammed e a ocidental Amy provocam também oscilação de sentimentos e uma reflexão sobre as relações interpessoais num clima de medo e de guerra. A paranóia inicial de Amy, que facilmente confunde muçulmanos com terroristas, atrai a compaixão do público para com o jovem muçulmano. No entanto, a insistência deste de que Amy o desviara do seu caminho utilizando a sua sexualidade como uma arma e que, por ser mulher e não ter a sua crença, as portas do Paraiso Ihe estariam vedadas, vai complicar esta compaixão.

Ravenhill leva-nos agilmente a entrar dentro desta narrativa para melhor criticar a falta de complexidade no tratamento destes temas nos media e na indústria cultural de hoje. Palavras-chave como "terrorismo" e imagens descontextualizadas de execuções já há muito substituíram o debate necessário sobre estas questões na esfera pública. 0 teatro tem um papel vital no relançar deste debate. Neste sentido, é curioso notar que há divergências entre este espectáculo e o texto anteriormente publicado, que não inclui a prisão de Mohammed. Supomos que os episódios de Guantanamo e Abu Ghraib contribuíram para a inclusão deste novo final, ilustrando o modo em que Producté um texto que, pela sua abertura, pode continuar a responder à actualidade social e politica. É claro que esta gloriosa sátira ao mundo de entretimento não escapa ela própria às contingências da indústria cultural contemporânea, sempre à procura de uma história cada vez mais inacreditável. Mas é verdade que, como este espectáculo sugeriu tão eficazmente, também se pode fazer excelente teatro a partir destas mesmas contradições.

\section{Referências bibliográficas}

RAVENHILL, Mark (2001), Plays: One, London, Methuen (inclui Shopping and Fucking, Faust is Dead, Handbag, Some Explicit Polaroids)

- - (2006), The Cut and Product, London, Methuen.

SIERZ, Aleks (2001), In-Yer-Face Theatre: British Drama Today, London, Faber and Faber. 